International Journal of Mechanical Engineering and Technology (IJMET)

Volume 12, Issue 01, January 2021, pp. 16-26. Article ID: IJMET_12_01_002

Available online at https://iaeme.com/Home/issue/IJMET?Volume=12\&Issue=1

ISSN Print: 0976-6340 and ISSN Online: 0976-6359

DOI: https://doi.org/10.34218/IJMET.12.1.2021.002

C IAEME Publication

Scopus Indexed

\title{
EFFECT OF DEEP CRYOGENIC TREATMENT ON MECHANICAL PROPERTIES OF 7075 ALUMINUM ALLOY
}

\author{
Shirish Patil \\ Mechanical Engineering, CSSMS, M.S, India \\ Vinay Lomte \\ Department of Chemical Technology, Dr. BAMU, M.S, India
}

\begin{abstract}
Aluminum alloys in various compositions displays different set of properties owing to its complex precipitation behavior during aging. Significant work has been performed by investigating the effects on various properties of ferrous metals like tool steels at cryogenic temperatures. As for Al alloys, the effects of cryogenic treatment on properties of age hardenable alloys like 7075are not reported extensively in current literature. This work consists of application of DCT at -185oC to 7075 aluminum alloy for various time durations. The cryogenic treatment was incorporated between the solutionizing and artificial aging of conventional T6 temper of Al alloy. This treatment sequence has been referred earlier in the literature for CT to 6061 Aluminum Alloy with significant improvements. The behavior of this alloy to the treatment was identified by measuring hardness, electrical conductivity and surface roughness. These measurement parameters were found to be significantly affected at specific cryogenic soaking duration and statistical analysis of experimental data supported the claim.
\end{abstract}

Keywords: Aging; Hardness; Conductivity; Roughness; Cryogenic.

Cite this Article: Shirish Patil and Vinay Lomte, Effect of Deep Cryogenic Treatment on Mechanical Properties of 7075 Aluminum Alloy, International Journal of Mechanical Engineering and Technology (IJMET), 12(1), 2021, pp.16-26.

https://iaeme.com/Home/issue/IJMET?Volume=12\&Issue=1

\section{INTRODUCTION}

Aluminum alloy have long been of prime interest due to its high strength to weight ratio and increased performance when compared to ferrous alloys. They display different set of properties in various compositions and are the major candidates in the aerospace community due to modest specific strength, manufacture ease and low cost. Aerospace industry demands improved performance and high specific properties [1]. The effects of cryogenic treatment (CT) to large 
extent on various ferrous alloys especially on tool steels and to some extent nonferrous alloys like Copper, Magnesium, Aluminum alloys, polymers and composites have been well under research. Cryogenic temperatures effects on properties of materials have been examined extensively in terms of mechanical, thermal and electrical properties [2,3]. Positive effects of low temperatures on this type of materials properties have led to the cold/sub-zero and cryogenic treatments of different variety of cutting tools and mechanic parts for increasing hardness, strength and wear resistance in automotive and manufacturing industry [3].

The sequential stages of basic CT consist of a gradual cooling of the component up to the defined temperature, holding for a given time (Soaking time) and progressively leading back to the room temperature to obtain an improvement of mechanical properties, specifically like hardness and wear resistance [4]. So, enhancement of metallurgical properties is obtained by CT to most of the metals, in turn improving several strengths of the treated parts [5]

As for aluminum alloys, formation of coherent precipitates in aging is mainly responsible for increase in strength and hardness. These coherent precipitates form from supersaturated solid solution after solutionising and quenching of age hardenable aluminum alloys like 2XXX, $6 \mathrm{XXX}$ and 7XXX series. So, material strengthening in these alloys is based on a precipitation hardening process. For 7xxx Al alloys, generally accepted precipitation sequence is like,

$7 X X X: \alpha_{\text {SS }} \longrightarrow \alpha+$ GP Zones $\longrightarrow \alpha+\eta^{\prime}\left(\mathrm{MgZn}_{2}\right) \longrightarrow \alpha+\eta\left(\mathrm{MgZn}_{2}\right)$

Where, GP zones are ordered solute-rich clusters of atoms responsible for appreciable elastic strains in the surrounding matrix [6]. So, if these alloys are treated at cryogenic temperatures there could be change in microstructure and subsequently in properties like the same way as "conditioning" of the matrix of the tool steels when subjected to the CT [6,7]. As precipitation is closely associated with dispersion and dissolution of solute particles in matrix of the alloy and changes due to $\mathrm{CT}$ are correlated to this precipitation behavior.

The important part here is when and how the CT should be incorporated in conventional heat treatment cycle of ferrous or nonferrous alloys. As for the ferrous alloys like steels and nonferrous alloys like Aluminum alloys, heat treatment comprising of austenitizing /solutionising and tempering / aging associated with dissolution and dispersion of precipitates can cause change in microstructure and properties. Inclusion of CT between quenching (after solutionising) and aging could affect the changes in the alloy and matrix "conditioning". It was evident by influential changes in some properties like hardness and surface roughness of $\mathrm{Al}$ 6061 when CT was given between quenching and aging [6]. As for $7075 \mathrm{AL}$ alloy, this initiated the present work for the following treatment cycle which investigates the response of this alloy to the CT.

As per available literature hold time over 36 hours at cryogenic temperatures does not bring significant improvements but in most cases 24 hours are enough to obtain results [4], so 20h,24h and $28 \mathrm{~h}$ were taken as cryogenic soaking durations.

The work comprises characterization by measuring the properties such as hardness, electrical conductivity and surface roughness. The response of the alloy to CT with respect to different properties under various treatment parameters is presented here.

\section{EXPERIMENTAL PROCEDURE}

The alloy used for the experimentation was an as-received commercial $7075 \mathrm{Al}$ alloy with a block of 250 by $250 \mathrm{~mm}$ with $30 \mathrm{~mm}$ thickness confirming to the composition by spectrometric analysis using ASTM B 209-01 (as shown in Table 1) from which two coupons each were prepared for different material/condition tested. It has undergone treatment of T6 and cryogenic cycle (SQCA - Solutionising + Quenching + Cryogenic Soaking + Artificial Aging). The heat treatment and cryogenic cycle are listed in Table 2. 
Effect of Deep Cryogenic Treatment on Mechanical Properties of 7075 Aluminum Alloy

Table 1 Composition of the AA 7075 used in the work

\begin{tabular}{|l|l|l|l|l|l|l|l|l|l|}
\hline Element & $\mathrm{Si}$ & $\mathrm{Fe}$ & $\mathrm{Cu}$ & $\mathrm{Mn}$ & $\mathrm{Mg}$ & $\mathrm{Cr}$ & $\mathrm{Zn}$ & $\mathrm{Ti}$ & $\mathrm{Al}$ \\
\hline Wt.\% & 0.05 & 0.16 & 1.67 & 0.45 & 2.13 & 0.12 & 6.08 & 0.03 & 89.3 \\
\hline
\end{tabular}

Table 2 Various heat treatment cycles applied to AA 7075 alloy

\begin{tabular}{|c|l|}
\hline Treatment Cycle & \multicolumn{1}{|c|}{ Process } \\
\hline T6 & $\begin{array}{l}\text { Solution-treatment at } 475^{\circ} \mathrm{C} \text { for } 1 \mathrm{~h}, \text { quenching in cold water at } \\
\text { room temperature, and aging at } 120^{\circ} \mathrm{C} \text { for } 24 \mathrm{~h}\end{array}$ \\
\hline $\begin{array}{c}\text { SQCA } \\
(\mathrm{CT} \mathrm{Cycle})\end{array}$ & $\begin{array}{l}\text { Solution-treatment at } 475^{\circ} \mathrm{C} \text { for } 1 \mathrm{~h}, \text { quenching in cold water at } \\
\text { room temperature, Cryogenic soaking at }-185^{\circ} \mathrm{C} \text { for } 20,24,28 \mathrm{~h} \text { and } \\
\text { aging at } 120^{\circ} \mathrm{C} \text { for } 24 \mathrm{~h},\end{array}$ \\
\hline
\end{tabular}

The hardness at various stages of the treatment was measured as per ASTM E18-03 on the Rockwell hardness tester on B scale, with 1/16th inch ball diameter and $100 \mathrm{~kg}$ load.

Electrical conductivity measurement (ASTM E1004-99) at various stages of the treatment was carried out by Techno four- Indian make electrical conductivity meter (type 979) for nonferrous metals in \% IACS. (International Annealed Copper Standard) The conductivity was measured in at random surfaces on each sample of cube and then averaged to obtain a conductivity number for the whole specimen.

The surface roughness was measured by a Mitutoyo make, Surf test SJ210 (stylus tip radius $5 \mathrm{~mm}$ ). Samples were machined on a vertical grinder with $0.25 \mathrm{~mm}$ depth of cut before the measurement of roughness (Ra value) after the treatments given.

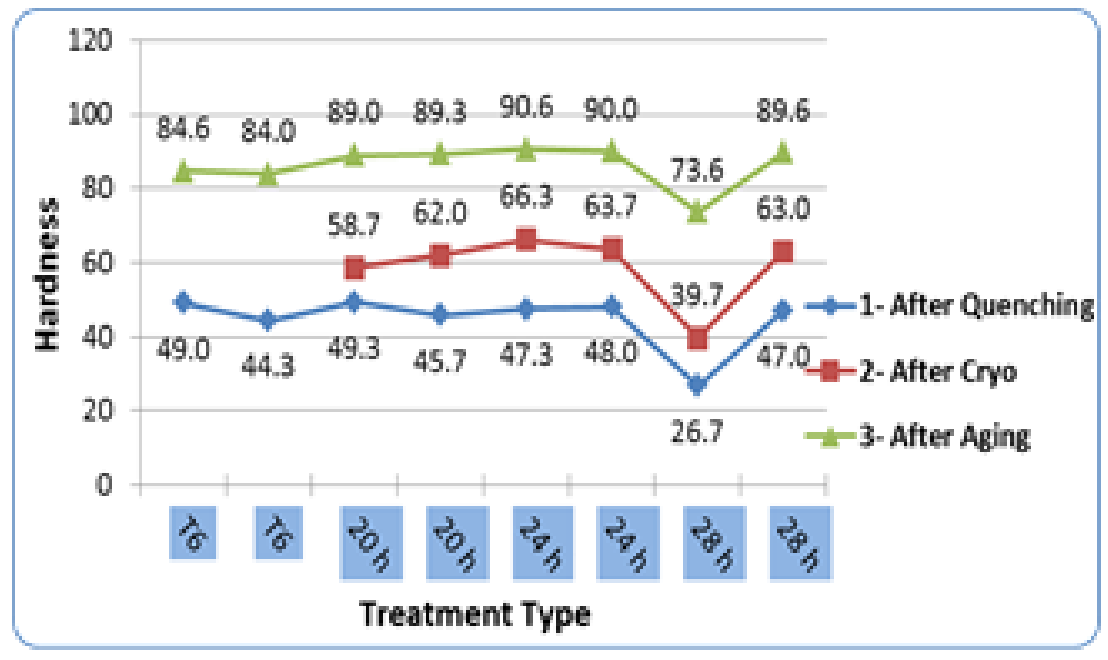

Figure 1 A Line chart shows different CT soaking periods for the hardness of AA 7075 compared to T6 


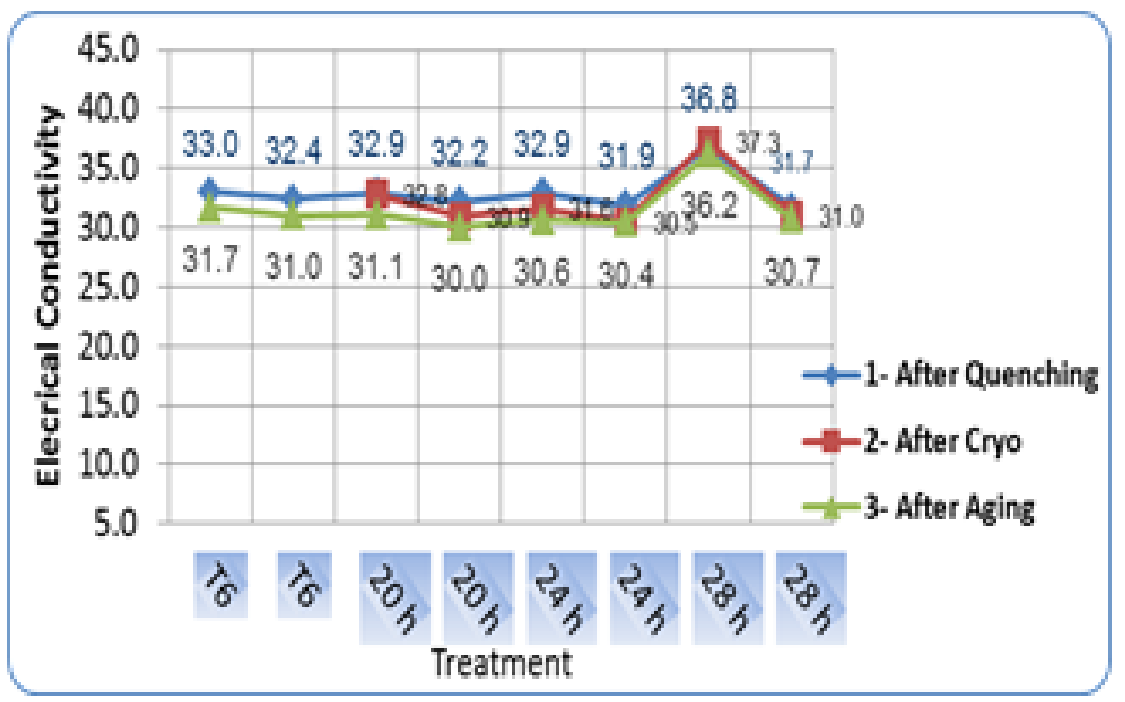

Figure 2 A Line chart shows different CT soaking periods for the electrical conductivity of AA 7075 compared to T6

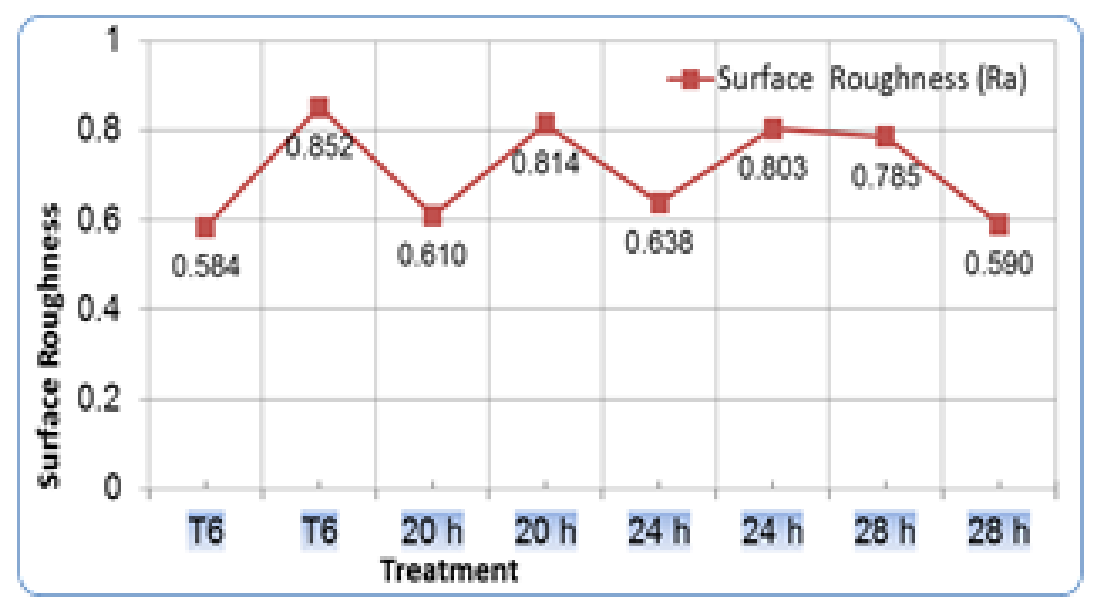

Figure 3 Surface Roughness for different CT soaking periods of AA 7075 compared with T6

\section{EXPERIMENTAL: PROPERTIES MEASUREMENT}

\subsection{Hardness}

Hardness measurements which were taken at subsequent intervals of treatment like after quenching, after cryogenic treatment and after aging to observe changes and effect of treatment on hardness. The treatment has exhibited increase in hardness for each subsequent treatment stage. $24 \mathrm{~h}$ cryogenically soaked (SQCA) sample had maximum hardness followed by $20 \mathrm{~h}$ after treatment compared T6 coupons Maximum increase in hardness was $7 \%$ for $24 \mathrm{~h}$ followed by about $6 \%$ for $20 \mathrm{~h}$ while reduction of $3 \%$ to $28 \mathrm{~h}$. Fine precipitation and optimum precipitate distribution contributed to improved hardness in cryogenically soaked (SQCA) samples over T6. The average and \% change in hardness of SQCA cube specimens is depicted in the chart 1 $28 \mathrm{~h}$

The effect of the treatment was checked for its consistency over longer duration. This was done by hardness measurements at periodic intervals to determine long-term (up to 6 months/180 days) stability of the properties on T6 and SQCA treated coupons. It was observed that the values of all coupons in T6 and 20, 24 and $28 \mathrm{~h}$ SQCA were fairly stable over the entire period. Increase in hardness after 180 days was approximately by $8 \%$ for T6 and 24Hrs samples. This graph shows that effect of treatment is consistent over longer duration. 


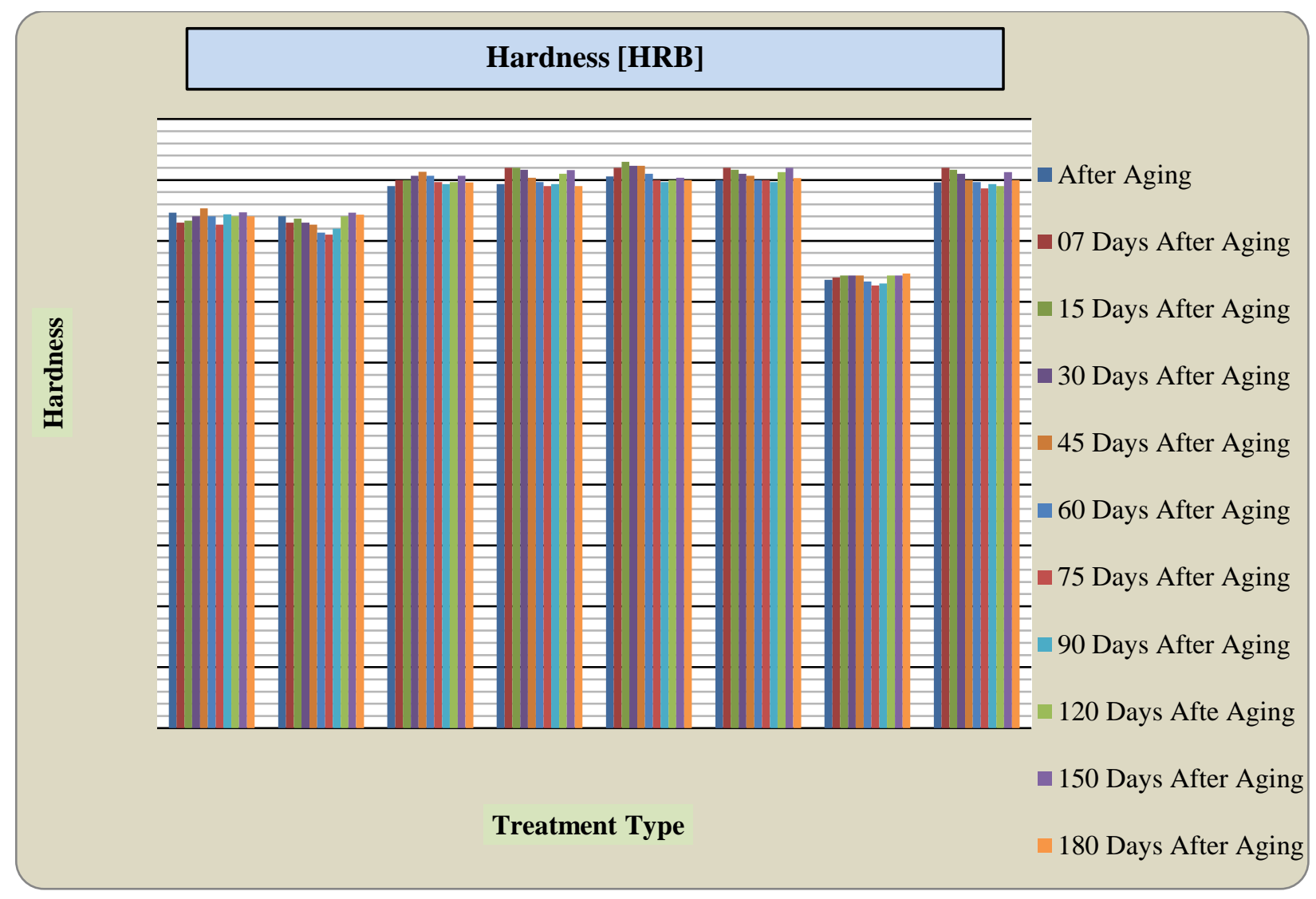

Figure 4

\subsection{Electrical Conductivity}

Measurements of electrical conductivity are helpful in heat treatment monitoring of aluminum alloys. Detection of flaws, micro structural changes are evident with change in the material conductivity. Also, for heat treated aluminum alloys higher values of electrical conductivity are indicative of good corrosion resistance.

Electrical conductivity at different treatment stages of T6 and SQCA samples displayed in graph6.2 showed that readings of all samples after aging are consequently less than the initial stages of treatment (quenching and cryogenic soaking). Conductivity decreases for each sample in each treatment stage, which is in accordance with ascending hardness values for respective samples in respective treatment stage for T6 and SQCA. So low electrical conductivity at higher hardness depicts dissolution of some precipitates which is attributed to the dissolution and reprecipitation phenomenon due to CT [7]. Maximum \% reduction is (approximately 3\%) for 24h followed by for $20 \mathrm{~h}$ but for $28 \mathrm{~h}$ increased by $7 \%$ approximately,

The highest average value (35.8) was for $28 \mathrm{Hrs}$ SQCA sample which had lowest hardness (73.9HRB) among all samples which is in accordance with earlier hardness, conductivity readings. There was no major fluctuation in conductivity readings at each time interval and all samples had constant conductivity over entire duration as shown in the graph. Variability in precipitate formation in microstructure for treated samples could be influential in electrical conductivity 


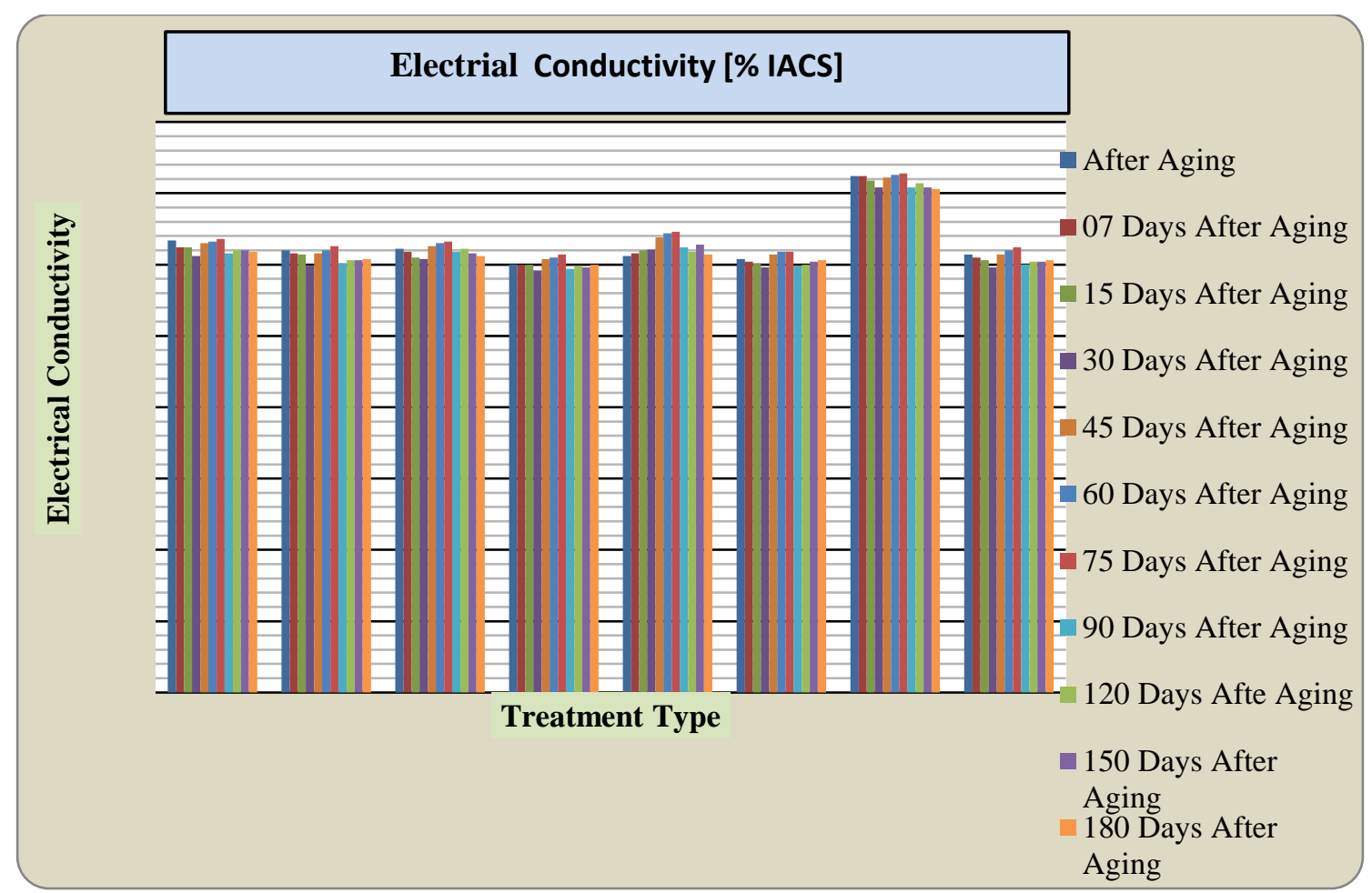

Figure 5

\subsection{Surface Roughness}

Roughness is a good predictor of the performance of a mechanical component, since irregularities in the surface may form nucleation sites for cracks or corrosion. Surface roughness measurements were taken by surface roughness tester after treatment i.e., T6 and Cryogenic treatment (SQCA). The $\mathrm{R}_{\mathrm{a}}$ values of roughness were measured in at least five random locations on single sample surface and then averaged to obtain a roughness value for the whole specimen. The measurement showed surface roughness $\mathrm{Ra}(\mu \mathrm{m})$ of T6 and SQCA treated samples on the single surface with small machining cut of $0.25 \mathrm{~mm}$. \% reduction compared to T6 was maximum for $28 \mathrm{hrs}(4 \%)$ followed by $20 \mathrm{hrs}(0.84 \%)$ while for $24 \mathrm{hrs}$ roughness increased $(0.28 \%)$. Lower Ra values for the sample of $24 \mathrm{~h}$ and to a small extent for $20 \mathrm{~h}$ indicate that cryogenic soaking after quenching and before aging could have helped to reduce roughness variably. Roughness reduction could be due to formation of large number of fine precipitates which helps in "filling up" of the gaps between coarser precipitates and uniform precipitate distribution [7].

The effect of the cryogenic treatment on the basic mechanical properties viz. hardness was significant, electrical conductivity was small as compared to the other treatments and the CT gave the additional benefit of improved surface roughness as observed for the sample of $24 \mathrm{~h}$ and $20 \mathrm{~h}$.

All the quantitative data collected from different tests and treatments at various conditions mentioned earlier was required to be analyzed on some statistical terms to find and establish co-relations between the sets of data so that some inferences could be drawn which would be helpful to gauge the effect of various treatments on properties and changes on the material. To determine whether the difference was a result of actual changes in the material or whether the observed differences were due to normal data variation (not a real difference), statistical

$t$-tests were performed. The $t$-test method performed for analyzing two sets of data to determine whether the difference in measured averages is real or a byproduct of chance variation some properties, albeit small. that there is about a 90-95\% confidence level $(t>1.75)$; 
that there was a difference in hardness ,electrical conductivity as a result of 48-h cryogenic treatment.

The SEM images show the Vacant lattice sites appearance after quenching which become more dominant due to CT, leading to formation of large number of vacancies, which ultimately forms fine precipitates in large quantities helping to increase hardness.

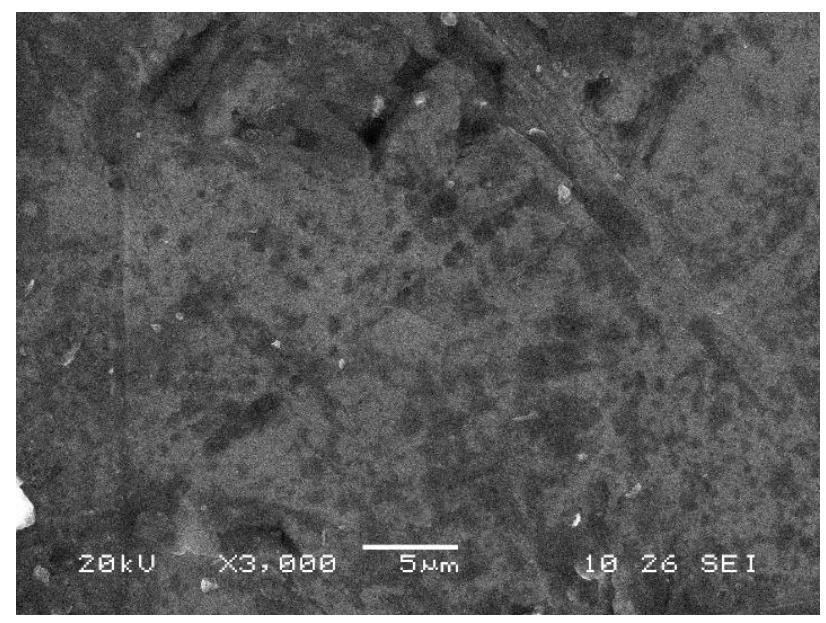

Figure 6 T6

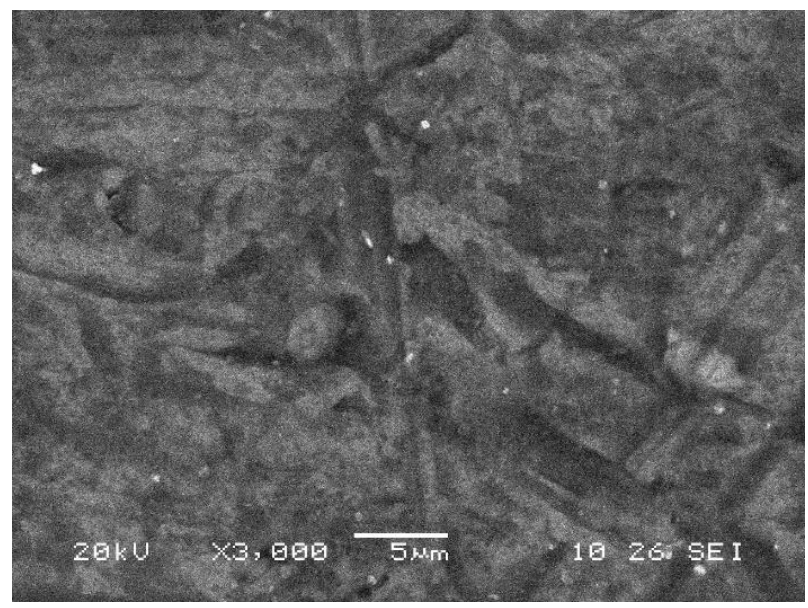

Figure $720 \mathrm{~h}$

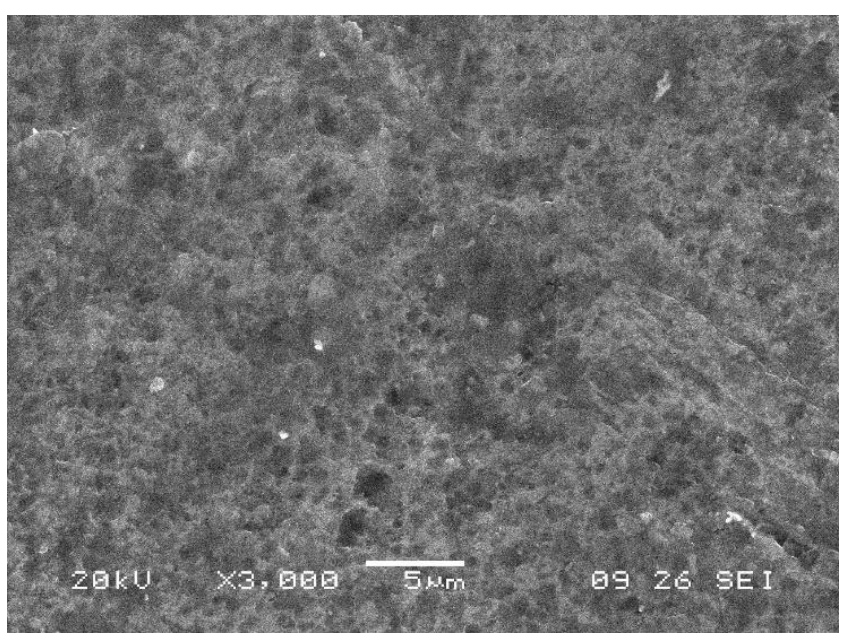

Figure $824 \mathrm{~h}$ 


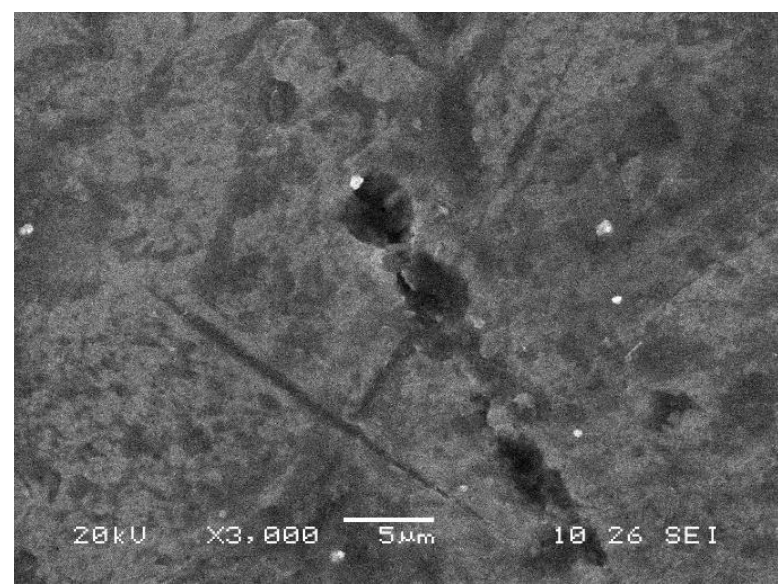

Figure $928 \mathrm{~h}$

\section{CONCLUSIONS}

When Aluminum alloy 7075 was cryogenically treated between solutionising and artificial aging (SQCA) for 20, 24 and 28h and compared to T6 and as-received condition, changes were observed for different properties which can be summarized and following conclusions can be drawn.

- There was considerable increase in hardness compared to T6 for all tested specimens for 20,24h SQCA but for 28h SQCA small increase in hardness observed for EXCO and tensile specimens while reduction for cube specimens. Fine precipitation from large number of vacancies due to CT helped to increase hardness.

- Electrical conductivity (EC) decreased compared to T6 for cube specimens for 20, 24h SCCA but for 28h SQCA there was substantial increase.

- Incoherent relationship between hardness \& EC was observed for different groups of test specimens such as for cube specimens inverse relationship was seen between hardness and EC (like increase in hardness, decrease in EC)

- As-received specimens showed inferior results than T6 and SQCA treated conditions for hardness, and EC

- Some of the above mentioned improved properties of SQCA samples over T6 appears to be a function of material itself in terms of chemical composition, cryogenic treatment and precipitate formation

- A high probability that $24 \mathrm{~h}$ CT could have a real effect on hardness, and to some extent by $20,28 \mathrm{~h} \mathrm{CT}$ to hardness and surface roughness.

\section{FUTURE SCOPE}

- More tests required to confirm that $24 \mathrm{~h} \mathrm{CT}$ indeed influences material properties of AA7075

- Effect of CT on fatigue and stress corrosion behavior could be tested

- Quantitative relationship between different processing parameters by CT can be found out

- Effect of CT on micro structural changes and characterization in 7XXX series Al alloys need to be investigated 
Effect of Deep Cryogenic Treatment on Mechanical Properties of 7075 Aluminum Alloy

\section{REFERENCES}

[1] P. Baldissera, C. Delprete, "Deep Cryogenic Treatment: A Bibliographic Review", The Open Mechanical Engineering Journal, 2008, 2, pp.1-11.

[2] Sundaram, M.-M., Yildiz, Y, Rajurkar K.-P., M. Nalbant "Experimental Study of the Effect of Cryogenic Treatment on the Performance of Electro Discharge Machining", MSEC 2009, West Lafayette, Indiana,USA

[3] Levine, J., 2001, Cryoprocessing Equipment, Heat Treating Progress, 2/1, pp.42-52

[4] Kaveh Meshinchi Asl, Alireza Tari, Farzad Khomamizadeh, "Effect of deep cryogenic treatment on microstructure, creep and wear behaviors of AZ91 magnesium alloy", Materials Science and Engineering A 523 (2009), pp.27-31.

[5] Wen-da ZHANG, Pei-kang BAI, Jing YANG, Hong XU, Jin-zhi DANG2, Zhen-min DU,” Tensile behavior of 3104 aluminum alloy processed by homogenization and cryogenic treatment", Trans. Nonferrous Met. Soc. China 24(2014), pp.2453-2458.

[6] Pavan.k.m, Sachin.l.s, Mayur.s, Chandrashekar.a, B.S.Ajaykumar, "Effect of Cryogenic Treatment On The Mechanical and Microstructural Properties of Aluminium alloys - a brief study", International Journal of Mechanical And Production Engineering, Volume- 2, Issue- 5, May-2014

[7] C. L. Gogte, Ajay Likhite, Dilip Peshwe, Aniruddha Bhokarikar \& Rahul Shetty, Effect of Cryogenic Processing on Surface Roughness of Age Hardenable AA6061 Alloy, Materials and Manufacturing Processes, Volume 29, Issue 6, 2014, pp.710-714.

[8] ASM Handbook Volume 2, Properties and Selection: Nonferrous Alloys and Special-Purpose Materials, ASM International

[9] E.A. Starke Jr,J.T. Staley, "Application of modern aluminum alloys to aircraft", Progress in Aerospace Sciences, Volume 32, Issues 2-3, 1996, pp. 131-172.

[10] Gary, J Spring "A Review of Deep Cryogenic Treatment of steels". Department of Mechanical Engineering, University of Texas at Austin. Accessed April 1999

[11] Kamody, D.J "Using Deep Cryogenic to Advantage," Advanced Materials \& Processes, 154:4, October 1998, pp.215-218.

[12] Engineers Edge, LLC, technical information, products and training, engineersedge.com/aluminum_tempers.htm (Web Article)

[13] D. Callister Jr, Fundamentals of Materials Science and Engineering, J. Wiley \& Sons, NY, $3^{\text {rd }}$ Ed. 2008

[14] Aluminum Standards and Data 2000 and or International Alloy Designations and Chemical Composition Limits for Wrought Aluminum and Wrought Aluminum Alloys, Metals Handbook, Vol.2 - Properties and Selection: Nonferrous Alloys and Special-Purpose Materials, ASM International 10th Ed. 1990.

[15] ASM Handbook, Vol. 2 - Heat Treating and Cleaning of Metals.

[16] Smith, Science and Engineering Materials, Chapter 8. 
[17] Flinn \& Trojan, Engineering Materials and Their Applications, Chapters 4 and 5.

[18] F.C. Campbell, Ed., Elements of Metallurgy and Engineering Alloys, ASM International, 2008.

[19] Patricia Mariane Kavalco, Lauralice C. F. Canale, George E. Totten "Quenching of Aluminum Alloys: Cooling Rate, Strength, and intergranular corrosion", Heat Treating Progress, November/December 2009.

[20] ME 3701, Materials of Engineering Laboratory, LSU.

[21] W.F. Smith, Foundations of Materials Science and Engineering, McGraw-Hill, Inc., 2nd Ed, New York, 1993.

[22] P. Hurath, J. Williams, T. Mackin and B. Coverdill, laboratory handout for ME-231.

[23] Polmear I.J, "Light Alloys: Metallurgy of The Light Metals", Elsevier Science, 3rd Edition.

[24] C.H.Gür, I. Yildiz,'Determining The Impact Toughness Of Age-Hardened 2024 Al-Alloy by Nondestructive Measurements" WCNDT 2004, Vol. 9 No.11, Nov 2004.

[25] Metal Suppliers Online (MSO), Industrial materials proprietary database, metalsuppliersonline.com/property pages/7075.asp (Web Article).

[26] Material Properties Data: 7075-T6 Aluminum,_Alcoa 7075 data sheet (PDF): accessed Oct. 13, 2006.

[27] Ferguson Perforating, perforated metal solutions, fergusonperf.com/the-perforatingprocess/material-information/aluminium-alloy_7075.asp (Web Article).

[28] Panchakshari H.V., Girish D.P., M Krishn,” Effect of Deep Cryogenic Treatment on Microstructure, Mechanical And Fracture Properties Of Aluminum-AL2O3 Metal Matrix Composites", International Journal of Soft Computing and Engineering (IJSCE) ISSN: 2231-2307, Volume-1, Issue-6, January 2012.

[29] P. Poza, J. Llorca "Fracture toughness and fracture mechanisms of Al-Al2O3 composites at cryogenic and elevated temperatures", Materials Science and Engineering: A, vol. 206 (2), (1996), pp.183-193.

[30] Cryogen Industries, cryogen.com.au/Cryogenic_Processing.htm (Web Article).

[31] D.N. Collins: "Cryogenic Treatment of Tool Steels," Adv. Mater. Processes, 1998, December, pp. H23-H29.

[32] Tarr, W.-R., Rhee, S.-K.” Thermal Conductivity Enhancement of Cu-0.85 Cr Alloy by Cryogenic Treatment, Proceedings of the Seventh Symposium on Thermophysical Properties", 1977 May 10-12, pp.135-140.

[33] Isaak, C.J., Reitz W.,'The Effects of Cryogenic Treatment on the Thermal Conductivity of GRCop-84", Materials and Manufacturing Processes, 2008, 23,pp.82-91.

[34] Abdulkareem, S., Khan, A., Konneh, M."Reducing electrode wear ratio using cryogenic cooling during electrical discharge machining," 2009, IJAMPT, 45/11,pp.1146-1151.

[35] Po Chen, Tina Malone, Robert Bond, Pablo Torres, "Effects of Cryogenic Treatment on the Residual Stress and Mechanical Properties of an Aerospace Aluminum Alloy", MSFC and National Aeronautics and Space Administration. 
Effect of Deep Cryogenic Treatment on Mechanical Properties of 7075 Aluminum Alloy

[36] Lulay, K.-E., Khan, K., Chaaya, D. "The Effect of Cryogenic Treatments on 7075 Aluminum Alloy, Journal of Materials Engineering and Performance", 200211/5, pp.479480 .

[37] M.U. Islam and W. Wallace," Retrogression and Re-aging response of 7475 aluminum alloy", Metals Technology, Vol. 10, 1983, pp. 386-392.

[38] M.U. Islam and W. Wallace, "Stress-Corrosion crack growth behavior of 7475-T6 retrogressed and reaged aluminum alloy", Metals Technology, Vol. 11, 1984, pp. 320-322.

[39] R.T. Holt, M.D. Raizenne and W. Wallace,” RRA Heat Treatment of Large Al 7075-T6 Components", RTO AVT workshop on New Metallic Materials for the Structure of Aging Aircraft, 19-20 April 1999, RTO kfp-25.

[40] Whitehouse, David (2012), Surfaces and their Measurement. Boston: Butterworth-Heinemann. ISBN 978-0080972015.

[41] ASTM G34-01, Standard Test Method for Exfoliation Corrosion Susceptibility in 2XXX and 7XXX Series Aluminum Alloys (EXCO Test).

[42] ASTM, Volume13 - Corrosion, Volume 13B - Corrosion Materials.

[43] Min Liao, Thomas Mills," Exfoliation Corrosion and Fatigue Modeling”, rto-ag-avt-140.

[44] ASTM G 1-03, Standard Practice for Preparing, Cleaning, and Evaluating Corrosion Test Specimens.

[45] B.K. Agrawal,”'Introduction to Engineering Materials “, Tata McGraw-Hill Edition, 2007, pp.11-14.

[46] ASTM E8, Standard Test Methods for Tension Testing of Metallic Materials.

[47] Xinyan Zhao, G.S. Frankel, Quantitative study of exfoliation corrosion: Exfoliation of slices in humidity technique, Corrosion Science 49 (2007), pp. 920-938.

[48] archive.bio.ed.ac.uk/jdeacon/statistics/tress4a.html (Web Article).

[49] Dr. David Stone \& Jon Ellis (at chem.utoronto.ca /coursenotes/analsci/StatsTutorial), Department of Chemistry, University of Toronto, August 2006 (Web Article).

[50] Investopedia, investopedia.com/terms/v/variance.asp (Web Article). 